\title{
Host specificity or habitat structure? - The epicortical beetle assemblages in an Australian subtropical rainforest
}

\author{
Florian MENZEL ${ }^{1,2}$, Roger L. KITCHING ${ }^{1}$ and SARAh L. BOULTER ${ }^{1}$ \\ ${ }^{1}$ Australian School of Environmental Studies, Griffith University, Nathan, Queensland 4207, Australia; \\ e-mail: r.kitching@griffith.edu.au \\ ${ }^{2}$ Department of Animal Ecology and Tropical Biology, Biozentrum Am Hubland, Julius-Maximilian's University, \\ 97074 Würzburg, Germany
}

Key words. Coleoptera, alpha diversity, bark, rainforest, Australia

\begin{abstract}
We have investigated the relative importance of bark roughness and host tree species in determining the diversity and make-up of coleopteran assemblages on the trunks of trees in sub-tropical rainforest in south-east Queensland, Australia. There are clear, statistically significant, patterns in the composition of the assemblages which reflect bark roughness. Rougher bark had associated greater species and family richness, a higher proportion of "rare" species, a higher value for Shannon diversity and lower values for the Simpson and Berger-Parker Index (measures of dominance within the sample). The data support strongly the idea that there is a bark-specific beetle assemblage. The rougher bark was associated with significantly greater numbers of an anobiid species, Dorcatoma sp., and of the latridiid species Aridius australicus. Rougher bark also harboured significantly larger species. The most likely explanation for this seems to be related to the physical heterogeneity and biological complexity of the habitat, presenting, as it does, greater opportunities for shelter, feeding specialisation and intra-species aggregation. Rougher bark contained a higher proportion of both predatory and xylophagous groups than did smoother categories. No clear influence of tree species could be detected although some trends were evident.
\end{abstract}

\section{INTRODUCTION}

It is no longer a matter for conjecture that the world's rainforests contain very large numbers of arthropod species, many of them undescribed and many to be encountered in the canopy (Erwin, 1982; Stork, 1987; Wilson, 1992). Debate continues on the absolute magnitude of this diversity (Erwin, 1991; Stork, 1988; Hammond, 1995; May, 1992; Ødegaard, 2000) but, for the most part, research attention has moved on to questions of the finer distribution patterns of arthropods within these forests and what the ecological determinants of these patterns might be (Kitching et al., 1997; Walter et al., 1998; Didham \& Springate, 2003; Novotný et al., 2003; Floren \& Linsenmair, 2003). A central issue in recent work has addressed the degree of compartmentalization of forest arthropod assemblages. Walter et al. (1998) addressed this question within sub-tropical rainforests demonstrating high degrees of complementarity (that is: betadiversity) of the parasitiform mite faunas of six different components of the forest ecosystem - the leaf litter, suspended humus, fungal sporocarps, leaf dwellers, arthropod associates and tree trunk dwellers - which were each compared with the fauna of the high canopy sampled by pyrethrum knockdown. These analyses showed that $89 \%$ of species inhabiting tree trunks were not found in canopy knockdown samples.

The bark surface of tree trunks has long been recognised as an important location for arthropods (and other animals) within the forest. Elton (1966) identified tree trunks as both "highways" and habitats for a range of species. Kitching et al. (2001) showed that, at the ordinal level, sampling of bark faunas was a good site to site discriminator for orthopteroid insects, for hemipteroids, Coleoptera, Diptera, Hymenoptera (other than ants), spiders and mites. Within particular Orders of arthropods, Watanabe (1997) working on Japanese coniferous forests and Rodgers \& Kitching (1998), working in Australian subtropical rainforests, showed that Collembola used trunks as highways and that clear ecological connections between the leaf litter on the ground and habitats in the high canopy do exist. These authors, of course, do not discount the possibility of a resident fauna on bark in addition to the passing parade of dispersers. Proctor et al. (2002), in drier Araucaria-dominated forests, also of subtropical Australia, showed that there was a highly distinct (and highly variable) assemblage of bark-related oribatid mites on tree trunks. Only one of a total of 32 morphospecies was shared in samples from bark and adjacent leaf litter. Earlier work on mites in other ecosystems also indicated a well defined corticolous assemblage (André, 1983, 1984). Well defined cortical or subcortical assemblages have been defined for other Orders of insects and arachnids, notably of Coleoptera, Diptera, Psocoptera and Araneae (eg. Basset, 1984; Baehr, 1990; Broadhead \& Thornton, 1955; Garrison \& Willig, 1996; Majer et al., 2003; New, 1970).

If well defined bark-based assemblages of arthropods exist, and it seems likely that they do, then the question arises as to what ecological factors are most influential in determining the structure of the assemblage for any particular taxon. Two hypotheses come to mind readily: that the bark structure is important and, second, that the tree 
species itself may impact upon the structure of the assemblage.

\section{The importance of bark structure}

Elton (1966) speculated upon the importance of bark structure commenting "the primary structure itself provides differing degrees and kinds of shelter in which insects, spiders and other small animals can hide themselves, their resting stages and their eggs". In other words the composition of an arthropod assemblage living on bark might well reflect on the "grain" of the environment (sensu Levins, 1968) with larger organisms treating rougher bark surfaces as less heterogenous (ie. more coarse grained) environments than do smaller organisms. Each bark surface will have a characteristic fractal dimension which will act as a selective force in determining, for example, the degree to which the physical environment may be subdivisible or, even, simply, usable by different species within an assemblage. These sensible conjectures have remained untested until relatively recently. Brown (1993), working in Australian subtropical rainforest, was unable to show any impact of bark structure or tree species on the species composition of psocopteran assemblages across nine species of tree which grouped into three levels of bark roughness. In contrast Baehr's (1990) qualitative assessments of carabid beetles associated with the trunks of various species of Eucalyptus (with various amounts of deciduous bark) suggested there was an association between bark structure and the set of organisms which occurred. Baehr's (1990) results were borne out in the studies of Majer et al. (2003) on Western Australian species of eucalypts who showed, somewhat counterintuitively that more smooth barked species supported greater numbers of invertebrates than rough-barked ones.

\section{The role of the tree species}

In contrast to the evaluation of the importance of bark structure, the hypothesis that tree species may have an impact on the composition of the fauna has a much wider literature. In recent studies of forest biodiversity most of this stems from Erwin's (1982) conjecture that there will be a usable average "level of host specificity" between a tree species and the arthropods which may be sampled from it. Recent studies and reviews (Novotný et al., 2002; Basset et al., 2003) have shown, for rainforests at least, that the levels of host specificity are nowhere near as high as earlier suggested by Erwin. Nevertheless there is an underlying, if low, pattern of arthropod-plant association which relates the diversity of arthropods in a forest to the species composition of the flora itself. When we restrict our considerations to the tree trunks alone, however, the association is much less convincing. In the case of psocids, as already observed, Brown (1993) found no effects of tree species on the assemblages for a range of subtropical rainforest trees in Australia, Majer et al. (2003) showed that some Orders of insects differed significantly in abundance across two smooth-barked species of Eucalyptus: notably the Homoptera, Diptera and non-ant Hymenoptera. New (1970), writing of temperate psocid assemblages, observed that although numbers of indi- viduals may vary greatly from tree species to tree species it is only in gross contrasts (such as conifer/angiosperm samples) that any species level differences in the associated arthropods become apparent. This lack of treespecific associations is, in fact, plausible given that most corticolous arthropods depend on the bark of the host tree only as a physical (that is: abiotic) resource: the vast majority are fungivores, herbivores or predators exploiting the associated biota of the bark rather than the bark itself.

In order to test the relative importance of these two interacting hypotheses, we have sampled the corticolous arthropods by insecticide spraying from nine species of subtropical rainforest trees in south-east Queensland (some of which are the same species studied by Brown, 1993). Trees were grouped into three levels of bark "roughness". We excluded any species with exfoliating bark as quantifying the degree of "roughness"; represented by such species was not possible.

\section{MATERIALS AND METHODS}

\section{Study site}

All work was carried out at Green Mountains adjacent to Lamington National Park in south-east Queensland, Australia $\left(28^{\circ} 13^{\prime} \mathrm{S} 153^{\circ} 07^{\prime} \mathrm{E}\right)$ at $600 \mathrm{~m}$ a.s.l. The substrate is a combination of laterite and basalt. The local climatic regime contrasts cool, drier winters with warm wet summers (annual mean rainfall $1623 \mathrm{~mm}$, annual maximum $31.2^{\circ} \mathrm{C}$, minimum $2.8^{\circ} \mathrm{C}$, mean monthly range $11.2-25.7^{\circ} \mathrm{C}$ ). The forest type is complex notophyll vine forest (sensu Webb et al., 1984) and the tree flora of the site has been described in detail by Laidlaw et al. (2000). The most abundant tree species were Actephila lindleyi, Randia benthamina and Baloghia inophylla although, in terms of basal area, the area was dominated by Argyrodendron actinophyllum, A. trifoliolatum, Pseudoweinmannia lachnocarpa, Caldcluvia paniculosa and Ficus watkinsiana. McDonald \& Whiteman (1979) designated the vegetation as an Argyrodendron trifoliolatum-A. actinophyllum-Caldcluvia paniculosa tall closed-forest alliance. All sampled trees are located within an area of approximately $500 \times 500 \mathrm{~m}$.

\section{Experimental design and sampling}

A balanced two-way design was used in which six replicates of each of nine species of trees were sampled. These nine species were grouped into three categories on the basis of their bark roughness with three species in each such grouping. Within any one class of bark roughness all species selected belong to different families to minimize potential influences of a priori "relatedness" (Table 1). Bark roughness was assessed using a simple index (RI) based on the comparison of the surface distance (SD - that is a linear distance obtained using fine cord tracking each irregularity in the bark) and a simple circumferential distance $(\mathrm{CD})$ of $50 \mathrm{~cm}$ around the tree, viz.:

$$
\mathrm{RI}=\frac{\mathrm{SD}-\mathrm{CD}}{\mathrm{SD}}
$$

This measure was made three times within the sampled quadrat on each tree sampled and a mean calculated. The three categories of trees, with "smooth", "intermediate" and "rough" bark respectively, showed between-group significant differences $(p<0.05)$ in these bark measures for all pairs of categories. Table 1 presents the tree species, their taxonomic affinities and these measures of bark roughness.

The bark fauna itself was sampled using the method described in detail by Kitching et al. (2000). The samples were obtained at 
TABLE 1. Tree species examined, their mean bark indices ( \pm 1 s.e.) and overall values for each bark type (see text).

\begin{tabular}{|c|c|c|c|c|}
\hline & Species & Family & Mean bark index & Bark type average \\
\hline \multirow[t]{3}{*}{ Rough } & Argyrodendron actinophyllum F. M. Bailey (Edlin) & Sterculiaceae & $0.0438 \pm 0.01033$ & $0.0590 \pm 0.00829$ \\
\hline & Diospyros pentamera (Woolls \& F. Muell.) F. Muell. & Ebenaceae & $0.0723 \pm 0.01418$ & \\
\hline & Synoum glandulosum (Smith) Adr. Juss. & Meliaceae & $0.0610 \pm 0.02319$ & \\
\hline \multirow[t]{3}{*}{ Intermediate } & Acradenia euodiiformis (F. Muell.) T. Hartley & Rutaceae & $0.0130 \pm 0.00205$ & $0.0157 \pm 0.00157$ \\
\hline & Caldcluvia paniculosa (F. Muell.) Hoogland & Cunioniaceae & $0.0156 \pm 0.00634$ & \\
\hline & Syzygium crebrinerve (C. T. White) L. A. S. Johnson & Myrtaceae & $0.0185 \pm 0.00421$ & \\
\hline \multirow[t]{3}{*}{ Smooth } & Cryptocarya obovata $\mathrm{R}$. Br. & Lauraceae & $0.0059 \pm 0.00239$ & $0.0061 \pm 0.00046$ \\
\hline & Geissois benthamii F. Muell. & Cunioniaceae & $0.0070 \pm 0.00272$ & \\
\hline & Orites excelsa $\mathrm{R} . \mathrm{Br}$. & Proteaceae & $0.0055 \pm 0.00197$ & \\
\hline
\end{tabular}

breast height and targeted a vertically orientated area, $1 \times 0.5 \mathrm{~m}$ in size. In choosing the bark sections to be sampled, bark covered with moss or lichen or with attached vascular epiphytes, was excluded as far as possible. A collecting "apron" made from an opened plastic bag was pinned along the bottom margin of this area with a collecting vial inserted in its vertex. The area was sprayed for about 15 seconds from about $0.5 \mathrm{~m}$ distance using a household insecticidal aerosol based on a mixture of simple pyrethrums with piperonyl butoxide and tetramethrin, bioallethrin, and bioresmethrin, respectively (Yates SLAY-A $\mathrm{FE}^{\mathrm{TM}}$ and MORTEIN ${ }^{\mathrm{TM}}$ ). The bark was subsequently brushed down over a period of 30 minutes, into the collecting funnel. The collections were carried out between March 27th and April 1 st, 2003.

Samples were returned to the laboratory in $80 \%$ ethanol. The Coleoptera were extracted and were subsequently mounted either by direct pinning or on points. These were identified to family and sorted to morphospecies (or "parataxonomic units" sensu Krell, 2004) within each family. The appropriateness of the morphospecies designations was checked by a practising taxonomist of the Coleoptera. A representative member of each morphospecies was measured from apex to abdomen tip using an eyepiece graticule.

\section{Data analysis}

Data derived from the counts and length measurements of beetles were analysed using a multidimensional scaling procedure within PATN for Windows 2.13 (Belbin, 1995). We calcu- lated sample-based rarefaction curves both for bark type and for each tree species using EstimateS (Colwell, 1997). A series of one-way analyses of variance were carried out using "bark roughness" and "tree species", respectively, as treatment variables followed by an LSD analysis based on t-tests wherever significant differences were indicated. It was not appropriate to carry out two-way analyses because the variables "bark roughness" and "tree species" were not independent of each other (nor could they be, given that bark properties are necessarily properties of the tree species).

The response variables analysed were the total number of beetles caught, total number of species on each trunk, proportion of "rare" species on each trunk (ie $=5$ individuals), number of individuals within the more abundant families (generally those with more than 30 individuals), and numbers of the commonest species (again with $>30$ individuals). We also calculated and analysed species richness (s), the Shannon index H', the Simpson index D and the Berger-Parker index. The Shannon index emphasizes the actual species richness and evenness, whereas the Simpson and Berger-Parker indices are more strongly influenced by the dominance of few species in the community. The Berger-Parker index is based on the relative abundance of the single most common species whereas the Simpson index, in contrast, yields a dominance measurement incorporating the range of commoner species (Magurran, 1988). We used both measures because many of our samples were indeed dominated strongly by a single species of latridiid beetle (see below). The data on the average length of the beetles on each

TABLE 2. Families of Coleoptera encountered: number of morphospecies, number of individuals.

\begin{tabular}{lcclcc}
\hline \multicolumn{1}{c}{ Family } & No. of morpho-species & No. of individuals & \multicolumn{1}{c}{ Family } & No. of morpho-species & No. of individuals \\
\hline Aderidae & 1 & 1 & Latridiidae & 6 & 1192 \\
Anobiidae & 1 & 88 & Leiodidae & 1 & 3 \\
Byrrhidae & 1 & 1 & Melandryidae & 1 & 1 \\
Carabidae & 3 & 17 & Melyridae & 1 & 3 \\
Chrysomelidae & 7 & 38 & Mycetophagidae & 1 & 54 \\
Clambidae & 1 & 1 & Nitidulidae & 4 & 56 \\
Corylophidae & 5 & 146 & Phalacridae & 1 & 17 \\
Cryptophagidae & 3 & 4 & Propalticidae & 1 & 1 \\
Curculionidae & 14 & 38 & Scydmaenidae & 10 & 25 \\
Discolomidae & 1 & 10 & Sphindidae & 2 & 13 \\
Elateridae & 3 & 5 & Staphylinidae & 16 & 2 \\
Endomychidae & 1 & 3 & Tenebrionidae & 2 & 12 \\
Eucnemidae & 1 & 1 & Throscidae & 1 & 1 \\
Jacobsoniidae & 1 & 14 & Zopheridae & 1 & \\
Laemophloeidae & 2 & 2 & & & 3 \\
\hline
\end{tabular}




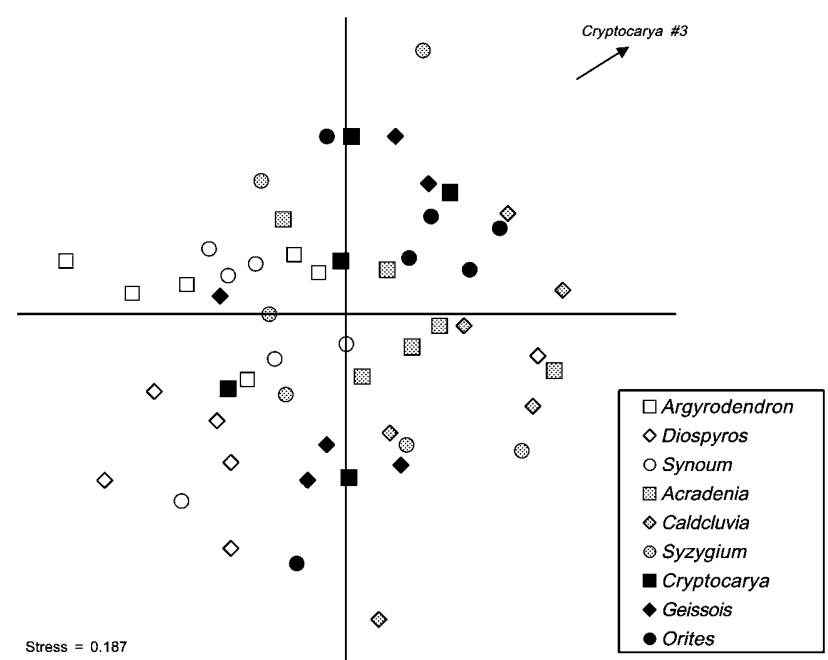

Fig. 1. Results of an ordination analysis by multidimensional shading. Open symbols show the results for the rough-barked trees; shaded symbols, the trees with bark of intermediate roughness; and, the black symbols, those with smooth bark.

tree were log-transformed before analysis. We tested whether there was a difference in average size of beetles (both of species and total individuals) of beetles across bark types.

All data expressed as proportions were arcsine transformed before analysis. Where multiple tests were carried out on nonindependent variables drawn from the same data set we used a Bonferroni correction on the critical probability value to minimize the likelihood of Type 1 errors. We used a critical value of $(0.5 / \mathrm{n})$ where $\mathrm{n}$ was the number of tests involved.

\section{RESULTS}

\section{The composition of the samples}

The samples contained 1877 beetles belonging to 29 families and 93 morphospecies. The family-level composition of the samples is summarised in Table 2. Nine families were represented by more than 20 individuals. Seven families were represented by a single individual. The most abundant morphospecies, a probably undescribed Aridius species ("Latridiidae \#1"), was represented by 1116 individuals $-59.5 \%$ of the entire sample. Only seven morphospecies were represented by more than twenty individuals and only 18 by more than ten. Forty-four morphospecies were represented by singletons.

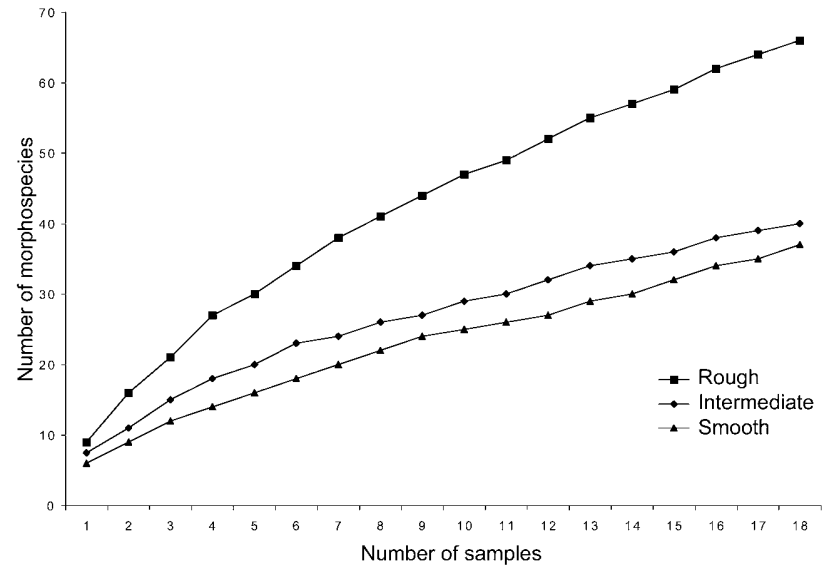

Fig. 2. Species rarefaction curves for each of the three types of bark investigated.

The most abundant families were the Latridiidae (63.5\%), Corylophidae (7.8\%), Staphylinidae (7.3\%), Anobiidae (4.6\%), Mycetophagidae (2.9\%) and Nitidulidae $(2.9 \%)$. No other family exceeded $2 \%$ of the total numbers encountered. The most species-rich families were the Staphylinidae $(17.2 \%$ of all species encountered), the Curculionidae (15.1\%) and the Scydmaenidae $(10.8 \%)$. No other family exceeded $10 \%$ of the total species found.

The numbers of each species encountered on individual trees has been analysed using multiple dimensional scaling (Belbin, 1995). Fig. 1 shows the results of such an ordination after Latridiid \#1 had been excluded. The results for a single tree that was positioned by the ordination remote from all the others has been excluded from the graphic although it was not excluded from the analysis. The three groups of trees (based on bark types) show a strong pattern. The strength of such a pattern can be assessed by calculating the stress value associated with the ordination. This is a technique which calculates a least squares fit to the deviations from a monotonic perfect fit between the dissimilarities and the distances between points in the multidimensional plot (ter Braak, 1995). A perfect fit has a stress value of zero. In this case the stress value was 0.1866 . Any value below 0.2 has generally been taken to indicate the existence of a strong and meaningful pattern.

TABLE 3. Morphospecies richness, family richness, proportions of rare species and diversity indices for each category of bark roughness, with the outcomes of one-way analyses of variance (see text).

\begin{tabular}{|c|c|c|c|c|c|c|}
\hline & Rough & Intermediate & Smooth & df & F-value & Probability \\
\hline Total number of morphospecies & 65 & 40 & 37 & & & \\
\hline Mean morphospecies richness per sample & $9.39 \pm 1.007$ & $7.22 \pm 0.521$ & $5.83 \pm 0.601$ & 2 & 5.85 & 0.0052 \\
\hline Total number of families & 26 & 10 & 19 & & & \\
\hline Mean family number per sample & $7.00 \pm 0.556$ & $5.83 \pm 0.351$ & $4.61 \pm 0.356$ & 2 & 5 & 0.0096 \\
\hline Mean proportion of rare morphospecies & $0.34 \pm 0.028$ & $0.21 \pm 0.027$ & $0.15 \pm 0.033$ & 2 & 11.17 & $<0.0001$ \\
\hline Total number of rare species & 43 & 21 & 19 & & & \\
\hline Simpson index & $0.30 \pm 0.031$ & $0.40 \pm 0.052$ & $0.52 \pm 0.044$ & 2 & 6.34 & 0.0035 \\
\hline Shannon Index & $1.63 \pm 0.097$ & $1.34 \pm 0.119$ & $1.02 \pm 0.106$ & 2 & 8.14 & 0.0009 \\
\hline Berger-Parker Index & $0.46 \pm 0.036$ & $0.54 \pm 0.05$ & $0.67 \pm 0.038$ & 2 & 6.25 & 0.0037 \\
\hline
\end{tabular}




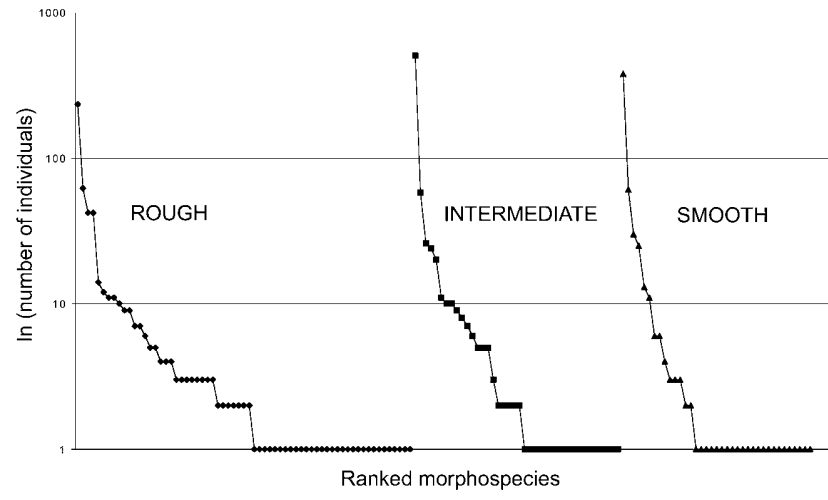

Fig. 3. Species/abundance curves for each of the three bark types.

\section{The importance of bark structure}

Species and family richness and diversity measures

Table 3 shows the results of analyses of variance of the diversity indices calculated plus the number of "rare" species (ie $\leq 5$ individuals), against bark roughness. All analyses show significant results. In every case the rough and smooth bark types showed significant differences from each other. In addition Shannon index and BergerParker index indicated a significant difference between the intermediate and smooth categories, whereas both mean species richness and the proportion of rare species showed a significant difference regarding rough versus intermediate bark.

Species rarefaction curves and rank/abundance plots

Fig. 2 shows the species rarefaction curves for three bark categories. These show a step-wise decline in diversity from rough, through intermediate to smooth categories. The beetle fauna becomes more speciose with increasing degree of bark roughness. Fig. 3 shows the rank/abundance plots for each category. The larger fauna of the rough barked trees contains more singletons than does either of the other categories. There is also a gradual increase in the slope of the central portion of the curves with diminishing bark roughness implying an increase in faunal evenness with increasing bark roughness.

Total abundance and abundance of selected taxa

The total number of individuals did not significantly differ between bark types (Table 4). We analysed the influence of the bark type at the family and morphospecies level, for each taxon that contained more than 30 individuals. We found interesting differences in the abun-

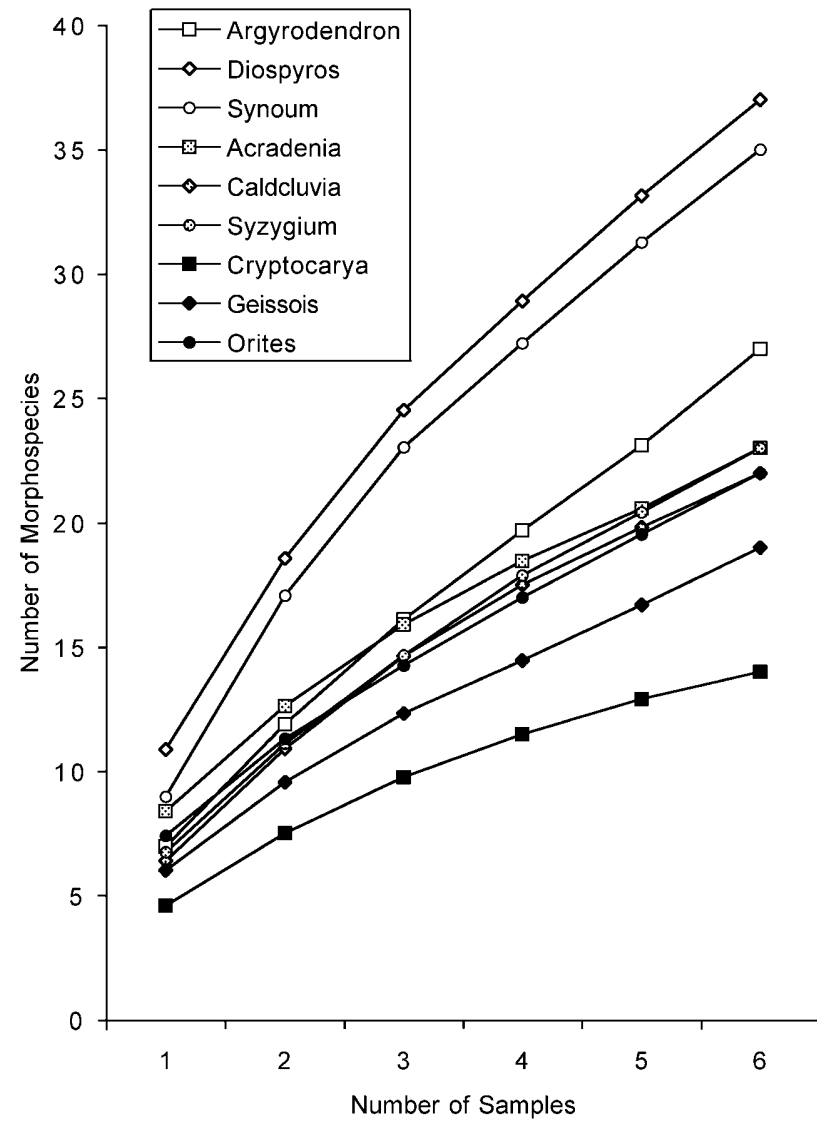

Fig. 4. Species rarefaction curves for each of the nine species of tree investigated.

dance of the Chrysomelidae (7 species) and the Anobiidae (1 species), which are shown in Table 4. Both indicate differences between rough and smooth bark types although after application of the appropriate Bonferroni correction (demanding a p cut-off of 0.0056) the results for the Chrysomelidae are to be regarded as a highly suggestive trend only. The Anobiidae, represented by a single species of the genus Dorcatoma, also showed a significant difference between rough and intermediate bark types. Also at the morphospecies level, the abundance of Aridius australicus (Latridiidae) on rough bark is significantly higher than on intermediate or smooth bark.

\section{Bark roughness and beetle size}

The length of the beetles encountered ranged from 0.77 to $13.69 \mathrm{~mm}$. Most of the species (29) are between 1.5

TABLE 4. Mean abundance of total individuals and certain taxa (with standard errors), and average sizes of beetles, across bark types level and associated ANOVA results (see text).

\begin{tabular}{lcccccc}
\hline & Rough & Intermediate & Smooth & df & F-value & Probability \\
\hline Abundance of Latrididae\#1 & 234 & 504 & 378 & 2 & 0.78 & n.s. \\
Mean number of individuals & $31.50 \pm 5.092$ & $41.11 \pm 11.611$ & $31.67 \pm 5.200$ & 2 & 0.32 & n.s. \\
Mean numbers of Anobiidae & $1.11 \pm 0.693$ & $0.33 \pm 0.309$ & $0.69 \pm 0.093$ & 2 & 8.97 & 0.0005 \\
Mean numbers of Chrysomelidae & $0.56 \pm 0.413$ & $0.17 \pm 0.136$ & $0.41 \pm 0.099$ & 2 & 3.92 & 0.026 \\
Mean numbers of Aridius australicus & $2.33 \pm 0.610$ & $0.28 \pm 0.195$ & $0.61 \pm 0.200$ & 2 & 8.1 & 0.0009 \\
Average size in mm & $1.88 \pm 0.055$ & $1.52 \pm 0.020$ & $1.49 \pm 0.025$ & 2 & 48.01 & $<0.0001$ \\
\hline
\end{tabular}


TABle 5. Assemblage Statistics for each tree species studied. Only the mean number of families per tree showed statistical significance $(\mathrm{p}<0.008$ after Bonferroni correction). The letters in column 6 indicate tree groupings based on significant differences.

\begin{tabular}{|c|c|c|c|c|c|}
\hline & Total species richness & Total family richness & Total number of rare species & Mean number of & milies \\
\hline Argyrodendron actinophyllum & 27 & 14 & 14 & $5.00 \pm 1.125$ & A B \\
\hline Diospyros pentamera & 37 & 19 & 21 & $8.50 \pm 1.176$ & A \\
\hline Synoum glandulosum & 35 & 19 & 17 & $7.50 \pm 0.885$ & A \\
\hline Acradenia euodiiformis & 23 & 13 & 9 & $6.67 \pm 0.760$ & A B \\
\hline Caldcluvia paniculosa & 22 & 14 & 9 & $5.33 \pm 0.615$ & A B \\
\hline Syzygium crebrinerve & 23 & 12 & 8 & $5.50 \pm 0.847$ & A B \\
\hline Cryptocarya obovata & 14 & 7 & 4 & $3.17 \pm 0.543$ & B \\
\hline Geissois benthamii & 19 & 12 & 7 & $4.83 \pm 0.703$ & A B \\
\hline Orites excelsa & 22 & 14 & 8 & $5.83 \pm 0.654$ & A B \\
\hline df & & & & 8 & \\
\hline F-value & & & & 3.51 & \\
\hline Probability & & & & 0.0031 & \\
\hline
\end{tabular}

and $2.0 \mathrm{~mm}$ long and most individuals (1394) range between 1.0 and $1.5 \mathrm{~mm}$.

We found a significant difference in the mean size of the individuals for each pairwise comparison. Also, rough bark showed a clearly higher variance in body size (Table 4). The mean size of the species did not significantly differ between bark types.

\section{The role of the tree species}

Species rarefaction curves and rank/abundance plots

Fig. 4 shows the species rarefaction curves for each of nine tree species. The highest and steepest curves belong to Diospyros and Synoum. The curve for Argyrodendron, though clearly below the former, rises above the remaining six species. All three of them have a high slope, indicating that they are far from saturation. The two lowest curves represent Geissois and Cryptocarya. Especially the latter shows that most of the species dwelling on Cryptocarya probably have been encountered. The curves for the remaining four tree species are rather similar in both slope and final value.

Species and family richness and various diversity measures

There were tree species to species differences among the mean number of beetle families encountered (Table 5) although the groupings generated are difficult to interpret. Strictly there were no tree species-specific differences that were significant for any of the indices calculated, for the mean number of species or for the mean proportion of "rare" species. If significance at the 0.05 level is taken as an indicator (rather than the Bonferroni-corrected value of $p=0.008$ ) then strong species-specific trends were apparent for the Shannon Index, the mean number of species per tree and the proportion of rare species. No other measures came close to showing significant differences.

Total abundance and abundance of selected taxa

There were no significant differences in abundance identified either for the total number of individuals per tree nor for any of the constituent lower taxa. Trends towards significant differences (ie $0.05>p>0.006$ ) were found for the Dorcatoma sp. (Anobiidae), the Corylophidae (5 species), the Chrysomelidae ( 7 species), the Mycetophagidae (1 species) and Aridius australicus (Latridiidae).

\section{DISCUSSION}

Bark roughness has a strong influence on the composition of the beetle assemblage. Species richness and evenness increased with increased bark roughness and, correspondingly, the levels of dominance decreased. Within the three tree species designated as "rough" this trend is maintained (Table 1, Fig. 4). We have shown clearly that the rougher the bark the greater the species diversity. The interesting question is: why should this be?

There could be a naïve physical explanation. The rougher the bark is then the greater will be the surface area targetted in a topical $0.5 \times 1 \mathrm{~m}$ area such as was sampled here. If we obtain correspondingly larger samples in terms of numbers of individuals then we might expect to encounter larger number of "rare" species as the "veil line" of the underlying distribution is gradually pulled back towards its origin (Gotelli \& Colwell, 2001; Magurran, 1988). This explanation is not supported by our data. We found almost the same numbers of individuals on rough and on smooth bark.

The more interesting ecological explanation is that the rougher the bark is then the more heterogeneous will be the environment and the more divisible (potentially) will be the associated niche space. This increase in heterogeneity might simply reflect a greater diversity of microclimates coexisting on rougher surfaces or it may act ecologically through the associated biota. This interpretation is borne out strongly in our data through two results. First there is a greater size range of beetles present on the rough bark (Table 4): not only are there significantly larger beetles in this assemblage but the associated variance in size is higher. This is, of course, not surprising: although a coarser physical environment may allow the persistence of larger individuals it will not, concomitantly, become any more or less inimicable to the species at the smaller end of the size range. The second 
piece of supporting evidence is secondary. If we transpose the beetle data on which our analyses are based into the feeding guilds of Hammond et al. (1997) then we find that the proportions of fungivores, herbivores and saprophages within the assemblages from the rough, intermediate and smooth bark are all very similar, one to the other and certainly show no trend which corresponds with bark roughness (fungivores 44, 46 and 55\% respectively; herbivores 34, 39 and 36\% respectively; saprophages 4,5 and $3 \%$ respectively). In contrast the predators show a clear trend downwards from rough to smooth bark $(8.5,4.4$ and $2.8 \%$ respectively). A similar trend is shown for the xylophages largely because of the patterns shown by the single bark feeding, anobiid species $(5,1.3$ and $0.7 \%)$. These figures are persuasive indications that there is a more complex and structured food-web on the rougher surfaces than on the smoother ones. It must be emphasised that these guild designations are coarse and that some simplifying rules of thumb have been applied in arriving at the figures (so, for example, where a family has members belonging to more than one feeding guild we have simply partitioned the sample equally among the guilds concerned). We would certainly not recommend any more sophisticated analyses upon the figures at this stage. Nevertheless the trends are there and present intriguing possibilities for future work.

The increase in assemblage evenness with bark roughness is of particular interest. Fig. 3 shows that this is largely a reflection of the greater proportion of species which exist in the middle range of densities on rougher bark surfaces. Again this may well reflect the greater resource base for populations of species within the bark community on these more heterogeneous surfaces. In other words the total number of individual beetles that can be supported is greater in the middle ranges of species abundances. This is not reflected in significant differences in terms of total beetles in the sample because of the dominance of all the samples by a few abundant species.

In contrast to our analyses on bark roughness the beetle assemblages we sampled showed no clear differences across tree species. This is not entirely surprising as most of the bark assemblage is dependent not on the tree itself but either on the non-living outer bark, epiphytic vegetation growing on the bark, or upon other corticolous invertebrates. It is possible that some xylophagous species could have high levels of host specificity but this is not apparent within our data and would only be resolved by detailed species-level studies. Similar lack of differences in beetle assemblages were observed by Majer et al. (2003) across four species of Western Australian Eucalyptus species.

In any sampling of a location such as tree trunks there will always be a question as to whether or not the insects encountered are "residents" or "transients". Only detailed, species-level studies can resolve this question. Nevertheless several families of Coleoptera show up in our analyses as having close associations both with the bark milieu in terms of both overall numbers and/or numbers of morphospecies in the sample. A subset of these (as has been discussed) show variation which correlates with the degree of bark roughness suggesting mechanisms, other than coincidence, underlying them. As indicated in Table 2 the common "bark families" are the Anobiidae, Chrysomelidae, Corylophidae, Curculionidae, Latridiidae, Mycetophagidae, Nitidulidae and Staphylinidae. The Scydmaenidae were species-rich but overall rather rare (as befits a predatory family). Of these families the Anobiidae, represented by a single species is likely to be a bark specialist. Members of the family are bark or fungus feeders and the statistically significant relationship with bark roughness is further evidence for their specialisation. The Corylophidae, Latridiidae and Mycetophagidae are all fungivorous as both larvae and adults and no doubt are associated with epiphytic fungi on or within the bark surface. The Latridiidae dominated the samples with one species showing a significant association with the measure of bark roughness. The Chrysomelidae, Curculionidae, Nitidulidae and Staphylinidae are all large, ecologically diverse families. Further interpretation of their role and dependence on the bark surface must await more detailed taxonomic analysis. The Scydmaenidae are generally thought of as predators and records exist of them preying upon mites (Lawrence \& Britton, 1991). We have no indication of what their prey might be within the bark system. Their high species diversity (10 species from 25 individuals) may imply a level of specialization in terms of prey or microhabitat.

The epicorticolous ecosystem is a fertile field for further study. A number of interesting questions have arisen during our study.

- What are the roles of species within families and how might these be linked functionally to components of the bark ecosystem?

- What roles do the amount, nature and diversity of bark epiphytes play in determining the biodiversity of particular groups of invertebrates on bark surfaces?

- To what extent are the patterns we have detected in coleopteran assemblages repeated within other diverse taxa - notably the Acari and Collembola?

- At what point do gross taxonomic differences in host plants (eg. between gymnosperms and angiosperms) override the structural relationships observed in our results?

- How do invertebrate assemblages respond to more complex bark types (eg. exfoliating, scaly)?

- How general across different ecosystems, are the beetle/bark relationships that we have established for subtropical rainforests?

The list of unanswered questions could be extended considerably. We suggest the ease of access and sampling of bark ecosystems make them ideal subjects for further study - subject to the availability of appropriate taxonomic expertise.

ACKNOWLEDGEMENTS. P. Grimbacher advised extensively on data collection and analysis. Peter assisted, in addition, in beetle identification. S. McKenna freely provided his botanical expertise. A. Creagh and J. McBroom supported the statistical 
analyses. P. Grimbacher and C. Long assisted in the field. We are deeply grateful to all these persons for their invaluable help. FM thanks the German National Academic Foundation (Studienstiftung des Deutschen Volkes) for financial support.

\section{REFERENCES}

ANDRÉ H.M. 1983: Notes on the ecology of corticolous epiphyte dwellers. 2. Collembola. Pedobiologia 25: 271-278.

ANDRÉ H.M. 1984: Notes on the ecology of corticolous epiphyte dwellers. 3. Oribatida. Acarologia 25: 385-395.

BAEHR M. 1990: The carabid community living under the bark of Australian eucalypts. In Stork N.E. (ed.): The Role of Ground Beetles in Ecological and Environmental Studies. Intercept Press, Andover, pp. 3-11.

BASSET Y. 1984: Contribution à la connaissance des peuplements sur Pinus mugo Turra dans les tourbières du Haut Jura Neuchatelois. Travail de Licence, Institut de Zoologie, Université de Neuchatel, $205 \mathrm{pp}$.

Basset Y., Hammond P.M., Barrois H., Holloway J.D. \& Miller S.E. 2003: Vertical stratification of arthropod assemblages. In Basset Y., Novotný V., Miller S.E. \& Kitching R.L. (eds): Arthropods of Tropical Forests: Spatio-Temporal Dynamics and Resource Use in the Canopy. Cambridge University Press, Cambridge, pp. 17-27.

Belbin L. 1995: PATN: Community Pattern Analysis Package. CSIRO Division of Wildlife and Ecology, Canberra, $234 \mathrm{pp}$.

BRAAK C.J.F. TER 1995: Ordination. In Jongman R.H.G, Braak C.J.F. Ter \& van Tongeren O.F.R. (eds): Data Analysis in Community and Landscape Ecology. Cambridge University Press, Cambridge, pp. 91-173.

BroadHEAd E. \& THORNTON I.W.B. 1955: An ecological study of three closely related psocid species. Oikos 6: 1-50.

Brown D.A.H. 1993: The Effects of Host Tree Species, Bark Type and Microepiphyte Cover on the Distribution and Abundance of Arthropod Taxa and Macroguilds on Tree Trunks in a Subtropical Forest. BSc Honours Thesis, Griffith University, Brisbane, $70 \mathrm{pp}$.

Colwell R.K. 1997: EstimateS: Statistical Estimation of Species Richness and Shared Species from Samples. Version 5. User's Guide and application, http://viceroy.eeb.uconn.edu./estimates

Didham R.K. \& Springate N.D. 2003: Determinants of temporal variation in community structure. In Basset Y., Novotný V., Miller S.E. \& Kitching R.L. (eds): Arthropods of Tropical Forests: Spatio-Temporal Dynamics and Resource Use in the Canopy. Cambridge University Press, Cambridge, pp. 28-39.

Elton C.S. 1966: The Pattern of Animal Communities. Methuen, London, $432 \mathrm{pp}$.

ERWIN T.L. 1982: Tropical forests: their richness in Coleoptera and other arthropod species. Coleopt. Bull. 36: 74-75.

ERwIN T.L. 1991: How many species are there: revisited. Conserv. Biodiv. 5: 330-333.

FLoren A. \& LinsenMair K.E. 2003: How do beetle assemblages respond to anthropogenic disturbance? In Basset Y., Novotný V., Miller S.E. \& Kitching R.L. (eds): Arthropods of Tropical Forests: Spatio-Temporal Dynamics and Resource Use in the Canopy. Cambridge University Press, Cambridge, pp. 190-197.

GaRRISON R.W. \& WILLIG M.R. 1996: Arboreal Invertebrates. In Reagan D.P. \& Waide R.B. (eds): The Food Web of $a$ Tropical Rain Forest. University of Chicago Press, Chicago, pp. 183-245.

Gotelli N.J. \& Colwell R.K. 2001: Quantifying biodiversity: procedures and pitfalls in the measurement and comparison of species richness. Ecol. Lett. 4: 379-391.
Hammond P.M. 1995: Magnitude and distribution of biodiversity. In Heywood V.T. \& Watson R.T. (eds): Global Biodiversity Assessment. Cambridge University Press, Cambridge, pp. $113-138$.

Hammond P.M., Kitching R.L. \& Stork N.E. 1997: The composition and richness of the tree-crown Coleoptera assemblage in an Australian subtropical forest. Ecotropica 2: 99-108.

Kitching R.L., Mitchell H., Morse G. \& Thebaud C. 1997: Determinants of species richness in assemblages of canopy arthropods in rainforests. In Stork N., Didham R. \& Adis J. (eds): Canopy Arthropods. Chapman and Hall, London, pp. 131-150.

Kitching R.L., Vickerman G., Laidlaw M. \& Hurley K. 2000: The Comparative Assessment of Arthropod and Tree Biodiversity in Old-World Forests: the Rainforest CRC/EARTHWATCH Protocol Manual. Technical Report, Cooperative Research Centre for Tropical Rainforest Ecology and Management, Cairns, 70 pp.

Kitching R.L., Li D.Q. \& Stork N.E. 2001: Assessing biodiversity "sampling packages": how similar are arthropod assemblages in different tropical rainforests? Biodiv. Conserv. 10: 793-813.

KRell F.-T. 2004: Parataxonomy vs taxonomy in biodiversity studies - pitfalls and applicability of "morphospecies" sorting. Biodiv. Conserv. 13: 795-812.

Laidlaw M., Olsen M., Kitching R.L. \& Greenway M. 2000: Tree floristic and structural characteristics of one hectare of subtropical rainforest in Lamington National Park, Queensland. Proc. R. Soc. Queensl. 109: 91-105.

Lawrence J.F. \& Britton E.B. 1991: Coleoptera (Beetles) In Naumann I. (ed.): Insects of Australia. Vol. 2. CSIRO, Melbourne, pp. 543-683.

Levins R. 1968: Evolution in Changing Environments, Princeton University Press, Princeton, $120 \mathrm{pp}$.

Magurran A.E. 1988: Ecological Diversity and its Measurement, Princeton University Press, Princeton, 179 pp.

Majer J.D., Recher H.F., Graham R. \& Gupta R. 2003: Trunk invertebrate faunas of Western Australian forests and woodlands: influence of tree species and season. Aust. Ecol. 28: 629-641.

MAY R.M. 1992: How many species inhabit the Earth. Scient. Am. 267: 42-48.

McDonald W.J.F. \& Whiteman W.G. 1979: Moreton Region Vegetation Map Series: Explanatory Booklet for Murwillumbah Sheet, Botany Branch, Department of Primary Industries, Brisbane, $58 \mathrm{pp}$.

NEw T.R. 1970: The relative abundance of some British Psocoptera on different species of trees. J. Anim. Ecol. 39: 521-540.

Novotný V., Basset Y., Miller S.E., Weiblen G.D., Bremer B., ČížEK L. \& Drozd P. 2002: Low host specificity of herbivorous insects in a tropical forest. Nature 416: 841-888.

Novotný V., Basset Y. \& Kitching R.L. 2003: Herbivore assemblages and their food resources. In Basset Y., Novotný V., Miller S.E. \& Kitching R.L. (eds): Arthropods of Tropical Forests: Spatio-Temporal Dynamics and Resource Use in the Canopy. Cambridge University Press, Cambridge, pp. 40-53.

ØDEGaARd F. 2000: How many species of arthropods? Erwin's estimate revisited. Biol. J. Linn. Soc. 71: 583-597.

Proctor H., Montgomery K., Rosen K. \& Kitching R.L. 2002: Are tree trunks habitats or highways? A comparison of oribatid mite assemblages from hoop-pine bark and litter. Aust. J. Entomol. 41: 294-299.

RoDGERS D.J. \& Kitching R.L. 1998: Vertical stratification of rainforest collembolan (Collembola: Insecta) assemblages: description of ecological patterns and hypotheses concerning their generation. Ecography 21: 392-400. 
Stork N.E. 1987: Arthropod faunal similarity of Bornean rain forest trees. Ecol. Entomol. 12: 219-226.

Stork N.E. 1988: Insect diversity: facts, fiction and speculation. Biol. J. Linn. Soc. 35: 321-337.

Walter D.E., Seeman O., Rodgers D. \& Kitching R.L. 1998: Mites in a mist: microhabitat distribution complementarity and body size distribution of Acari from a subtropical rainforest. Aust. J. Ecol. 23: 501-508.

Watanabe H. 1997: Estimation of arboreal and terrestrial arthropod densities in the forest canopy as measured by insec- ticide smoking. In Stork N., Didham R. \& Adis J. (eds): Canopy Arthropods. Chapman and Hall, London, pp. 401-414.

Webb L.J., Tracey J.G. \& Williams W.T. 1984: A floristic framework of Australian rainforests. Aust. J. Ecol. 9: 169-198.

WiLson E.O. 1992: The Diversity of Life. Harvard University Press, Cambridge, Mass., 424 pp.

Received September 9, 2003; revised March 18, 2004; accepted March 23, 2004 